\title{
Pengaruh Kepemimpinan Transformasional dan Transaksional pada Kinerja Pegawai Bappeda Kota Bandung
}

\author{
Ina Ratnamiasih \\ Fakultas Ekonomi Universitas Pasundan \\ Jl. Tamansari No. 6-8, Bandung 40116 \\ E-Mail: inaratnamiasih@gmail.com \\ Warenih \\ E-Mail: enih.penol@yahoo.co.id
}

\begin{abstract}
Leadership in government institution increasingly recognized role in improving employee performance. As one of the organizations responsible for performing research and development planning for local development, Bappeda need leaders who are able to use the leadership style. This study aims to look at the effect of transformational and transactional leadership on employee performance Regional Development Planning Board (Bappeda) in Bandung. Data was collected using a census technique on all employees of the Bappeda totaling 88 people. Data were analyzed using Structural equation modeling (PLS). The results showed a positive and significant influence of transformational and transactional leadership on employee performance. Transactional leadership has a greater influence than the transformational leadership. The next study is expected to use different methods in order to more clearly the contribution of leadership on employee performance, especially in government institution.
\end{abstract}

Keywords: transformational leadership, transactional leadership, job performance.

\begin{abstract}
ABSTRAK
Kepemimpinan pada organisasi pemerintahan semakin diakui perannya dalam meningkatkan kinerja pegawai. Sebagai salah satu organisasi yang berfungsi melakukan perencanaan dan pengembangan penelitian untuk pembangunan daerah, maka Bappeda Kota Bandung membutuhkan pemimpin yang mampu menggunakan gaya kepemimpinan yang tepat. Penelitian ini bertujuan untuk melihat pengaruh kepemimpinan transformasional dan kepemimpinan transaksional terhadap kinerja pegawai Badan Perencanaan Pembangunan Daerah (Bappeda) di Kota Bandung. Data dikumpulkan dengan menggunakan teknik sensus pada seluruh pegawai Bappeda kota Bandung yang berjumlah 88 orang. Data dianalisis dengan menggunakan regresi linier berganda. Hasil penelitian menunjukkan adanya pengaruh yang positif dan signifikan dari kepemimpinan transformasional dan transaksional pada kinerja pegawai. Kepemimpinan transaksional lebih besar pengaruhnya dalam meningkatkan kinerja pegawai. Penelitian berikutnya diharapkan dapat menggunakan metode yang berbeda agar lebih jelas kontribusi kepemimpinan pada kinerja pegawai pada organisasi pemerintah.
\end{abstract}

Kata Kunci: kepemimpinan transformasional, kepemimpinan transaksional, kinerja pegawai. 


\section{PENDAHULUAN}

Pegawai dalam suatu organisasi merupakan sumber daya terpenting dalam pencapaian tujuan (Robbins, 2008). Rencana yang dibuat untuk mencapai tujuan hanya dapat dijalankan jika setiap anggota organisasi dapat bekerja sama dan berkoordinasi dengan baik. Di lain pihak, salah satu permasalahan yang dihadapi oleh organisasi adalah bagaimana meningkatkan kinerja pegawai. Kinerja adalah hasil kerja secara kualitas dan kuantitas yang dicapai oleh seseorang pegawai dalam melaksanakan tugasnya sesuai dengan tanggung jawab yang diberikan kepadanya (Mangkunegara, 2009). Dalam meningkatkan kinerja pegawai perlu direncanakan suatu strategi dan pengelolaan yang baik. Untuk itu dalam mencapai tujuan, seluruh sumber daya yang ada harus dapat dimanfaatkan sebaik mungkin termasuk sumber daya manusia sebagai faktor utama.

Kinerja merupakan suatu hasil dari aktivitas kerja pegawai berdasarkan tugas dan tanggung jawab yang diberikan (Sedarmayanti, 2007). Dengan kinerja yang baik, maka setiap pegawai dapat menyelesaikan segala beban organisasi. Peningkatan kinerja juga akan dapat meningkatkan efektivitas dan efisiensi pelaksanaan pekerjaan yang pada akhirnya akan menguntungkan organisasi. Pentingnya kinerja pegawai dirasakan pula oleh Badan Perencanaan Pembangunan Daerah (Bappeda) Kota Bandung yang mempunyai tugas pokok membantu Walikota dalam menyelenggarakan Pemerintah Kota Bandung di bidang perencanaan pembangunan. Disamping itu, Bappeda berperan sebagai lembaga teknis daerah yang bertanggung jawab terhadap perencanaan pembangunan sebagaimana diamanatkan dalam pasal 14 ayat (1), Undang-Undang Nomor 32 Tahun 2004 tentang Pemerintahan Daerah, yang menyatakan bahwa salah satu urusan wajib yang menjadi kewenangan pemerintah daerah adalah urusan perencanaan dan pengendalian pembangunan. Salah satu tugas Bappeda adalah menyelenggarakan musyawarah perencanaan dan pengembangan (Musrenbang) jangka panjang.

Musrenbang sangat penting dalam pencapaian tujuan instansi, yaitu untuk meningkatkan pelayanan terhadap masyarakat terutama dalam proses perencanaan pembangunan agar target dapat dicapai. Selain itu, kinerja pegawai di Bappeda Kota Bandung sangat penting karena kinerja pegawai akan menentukan keberhasilan suatu organisasi, terutama bagi organisasi publik seperti Bappeda Kota Bandung. Pentingnya kinerja pegawai menyebabkan Bappeda Kota Bandung dituntut untuk melaksanakan manajemen sumber daya manusia (SDM) yang tepat.

Kinerja pegawai menjadi perhatian Bappeda kota Bandung. Namun, berdasarkan hasil wawancara dengan kepala sekretariat dapat di identifikasikan masalah yang menimbulkan kinerja pegawai kurang optimal. Secara kualitas, masalah kinerja yang ditemui adalah pegawai kurang teliti dalam mengerjakan tugas. Ketelitian yang kurang dapat dilihat dari masih seringnya terjadi kesalahan dalam mengolah data sehingga banyak koreksi dari atasan. Masalah lain yang terjadi adalah masih adanya pegawai yang tidak mendahulukan pekerjaan. Masih ditemukan pegawai yang lebih mementingkan kepentingan pribadi dengan meninggalkan tanggung jawab dalam melaksanakan tugas dengan melimpahkannya pada pegawai lain. Selain itu, masalah lain yang terjadi kurang inisiatifnya pegawai dalam mengerjakan tugas, dapat dilihat dari adanya pegawai yang masih harus selalu diperintah atasan dalam melaksanakan tugasnya. Disamping beberapa permasalahan kinerja yang telah disebutkan sebelumnya, masih ditemui beberapa kendala dan permasalahan dalam peningkatan kinerja Bappeda, antara lain: rendahnya tingkat aplikasi dokumen perencanaan pembangunan, rendahnya tingkat aplikasi dokumen penelitian dan kajian yang dihasilkan oleh Bappeda, dan belum optimalnya tingkat pengelolaan daerah yang terintegrasi dari hulu hingga hilir dari proses perencanaan pembangunan daerah, pelaksanaan anggaran, pengawasan anggaran serta penilaian kinerja pelaksanaan anggaran berbasis teknologi informasi.

Kepemimpinan seringkali dianggap sebagai driver (Raja et al., 2007). Kepemimpinan menggambarkan hubungan antara pemimpin dengan yang dipimpin dan bagaimana seorang pemimpin mengarahkan follower akan menentukan sejauhmana follower mencapai tujuan atau harapan pimpinan (Bass et al., 2003). Konsep kepemimpinan yang berkembang pesat adalah konsep kepemimpinan transformasional dan transaksional yang dipopulerkan oleh Bass (Locander et al., 2002).

Kepemimpinan transformasional menyerukan nilai-nilai moral dari pengikut dalam upayanya untuk meningkatkan kesadaran mereka tentang masalah 
etis dan untuk memobilisasi energi dan sumber daya mereka untuk mereformasi institusi. Karakteristik pemimpin transformasional dapat dilihat dari kharisma, Inspirasi, stimulasi, dan pertimbangan individual (Robbins, 2008). Irawati dan Liana (2013), Muhardi dan Siregar (2013), Pradana et al. (2013) menyatakan bahwa kepemimpinan transformasional adalah pemimpin yang memotivasi bawahannya dan mengubah individu meningkatkan dirinya agar lebih semangat didalam bekerja serta memberi dorongan untuk tidak mendahulukan kepentingan pribadi akan tetapi untuk mencapai tujuan organisasi.

Kepemimpinan transaksional melakukan transaksi memotivasi para pengikut dengan menyerukan kepentingan pribadi (Locander et al., 2002). Maulizar et al. (2012) kepemimpinan transaksional adalah model kepemimpinan di mana seorang pemimpin cenderung memberikan arahan kepada bawahan, serta memberi imbalan dan hukuman atas kinerja mereka serta menitik beratkan pada perilaku untuk memandu pengikut mereka ke arah tujuan yang ditetapkan dengan memperjelas peran dan tuntutan tugas. Karaktersitik yang dapat dilihat dari kepemimpinan transaksional antara lain: imbalan kontingen, manajemen berdasarkan pengecualian (aktif), manajemen berdasarkan pengecualian (pasif), Laissez-Faire (Robbins, 2008).

Faktor kepemimpinan juga diindikasikan menjadi salah satu faktor kurang optimalnya kinerja pegawai. dari hasil wawancara dengan pegawai staf bagian umum di Bappeda Kota Bandung. Terlihat permasalahan masih kurangnya pimpinan dalam memberikan ketegasan didalam memimpin, sehingga banyak pegawai yang mengesampingkan tugasnya dalam melaksanakan tanggung jawabnya dan lebih mementingkan kepentingan pribadinya. Dilihat dari seringnya pegawai yang terlambat datang dan mengutamakan kepentingkan lain daripada tanggung jawabnya terhadap tugas yang diberikan akan tetapi tidak adanya sanksi tegas yang diberikan kepada pegawai yang sering menunda pekerjaannya. Permasalahan lain juga pemimpin kurang dalam memenuhi imbalan kepada pegawainya ini terlihat dari pegawai yang sering berprestasi dalam kinerjanya dengan pegawai yang biasa-biasa saja akan tetapi kompensasi yang diberikan sama. Sementara berdasarkan keputusan Gubernur Jawa
Barat Nomor: 910/Kep.1274-Admbang/2009 tentang Standar Biaya Belanja Daerah Pemerintah Provinsi Jawa Barat Tahun Anggaran 2010, PNS di Pemerintah Provinsi Jawa Barat memperoleh tunjangan tambahan penghasilan dan kompensasi uang makan yang jumlahnya bervariasi. Pemerintah daerah dapat memberikan tambahan penghasilan kepada pegawai negeri sipil berdasarkan pertimbangan yang obyektif dalam rangka peningkatan kesejahteraan pegawai. Hal ini menunjukkan kepemimpinan transaksional yang diterapkan di Bappeda yang beraitan dengan penerapan sistem kompensasi kurang sesuai dengan keputusan yang diberikan oleh pemerintah. Selain itu, jam kerja pegawai sering melewati batas yang ditentukan, dimana pegawai yang bekerja diluar batas waktu tetapi tidak dihitung lembur sehingga tidak ada timbal balik yang diperoleh pegawai.

Berdasarkan latar belakang permasalahan yang telah diuraikan, maka secara umum permasalahan yang dapat dirumuskan adalah bagaimana kinerja pegawai Bappeda Kota Bandung dapat ditingkatkan dengan mempertimbangkan kepemimpinan transformasional dan kepemimpinan transaksional. Penekanan studi lebih pada bagaimana kepemimpinan berperan dalam upaya mendorong SDM agar memiliki kinerja yang baik. Teori kepemimpinan transformasional dan transaksional merupakan teori yang telah banyak diadopsi (Blankenship, 2010; Breaux, 2009; Chen, 2004; Hancock, 2008; Kim, 2009). Beberapa studi kepemimpinan transformasional dan transaksional lainnya yang sudah pernah dilakukan dapat dilihat pada Tabel 1. Sebagian besar penelitian terdahulu menunjukkan bahwa kepemimpinan transformasional terbukti efektif dalam mendorong bawahan untuk mencapai tujuan (Avolio et al., 1999). Pemimpin transformasional berinteraksi menggunakan pendekatan emosional untuk menstimulasi pengembangan intelektual bawahan (Ho et al., 2009; Sağnak, 2010).

\section{METODE}

Penelitian dilaksanakan pada Badan Perencanaan Pembangunan Daerah (Bappeda) Kota Bandung. Objek penelitian ini adalah kinerja pegawai, kepemimpinan transformasional dan transaksional pada Bappeda Kota Bandung. 
Tabel 1. Dimensi Penelitian Kepemimpinan Transformasional dan Transaksional

\begin{tabular}{|c|c|c|c|c|}
\hline Dimensi & Peneliti (Tahun) & Dimensi Serupa & Peneliti (Tahun) & Dimensi Penelitian \\
\hline $\begin{array}{l}\text { Idealized influence } \\
\text { (charisma) }\end{array}$ & $\begin{array}{l}\text { Blankenship, 2010; Firestone, 2010; } \\
\text { Ho et al; Perkins, 2010; Fesharaki et al., } \\
\text { 2013: Fitzgerald, D. T., 2009; Sagnak, } 2010\end{array}$ & Charisma & Scott, 2010 & $\begin{array}{l}\text { Idealized influence } \\
\text { (charisma) }\end{array}$ \\
\hline \multirow[t]{2}{*}{$\begin{array}{l}\text { Inspirational } \\
\text { motivation }\end{array}$} & \multirow{2}{*}{$\begin{array}{l}\text { Blankenship, 2010; Firestone, 2010; } \\
\text { Ho et al; Perkins, 2010; Fesharaki et al., } \\
\text { 2013: Fitzgerald, D. T., 2009; Sagnak, } 2010\end{array}$} & $\begin{array}{l}\text { Visionary- } \\
\text { inspirational }\end{array}$ & Hunt, 2010 & \multirow[t]{2}{*}{$\begin{array}{l}\text { Inspirational } \\
\text { motivation }\end{array}$} \\
\hline & & Vision & Scott, 2010 & \\
\hline \multirow{2}{*}{$\begin{array}{l}\text { Intellectual } \\
\text { stimulation }\end{array}$} & \multirow{2}{*}{$\begin{array}{l}\text { Blankenship, 2010; Firestone, 2010; } \\
\text { Ho et al; Perkins, 2010; Fesharaki et al., } \\
\text { 2013: Fitzgerald, D. T., 2009; Sagnak, } 2010\end{array}$} & Intelligent & Scott, 2010 & \multirow{2}{*}{$\begin{array}{l}\text { Intellectual } \\
\text { stimulation }\end{array}$} \\
\hline & & Risk taking & Scott, 2010 & \\
\hline \multirow{3}{*}{$\begin{array}{l}\text { Individualized } \\
\text { consideration }\end{array}$} & \multirow{3}{*}{$\begin{array}{l}\text { Blankenship, 2010; Firestone, 2010; } \\
\text { Ho et al; Perkins, 2010; Fesharaki et al., } \\
\text { 2013: Fitzgerald, D. T., 2009; Sagnak, } 2010\end{array}$} & Supportive & Scott, 2010 & \multirow{3}{*}{$\begin{array}{l}\text { Individualized } \\
\text { consideration }\end{array}$} \\
\hline & & $\begin{array}{l}\text { Participative } \\
\text { (democratic- } \\
\text { participative) }\end{array}$ & $\begin{array}{l}\text { Hunt, 2010; Rad dan } \\
\text { Yarmohammadian, } \\
\text { 2006; Clark et al. }\end{array}$ & \\
\hline & & Empowering & Clark et al. & \\
\hline Contingent reward & $\begin{array}{l}\text { Blankenship, 2010; Firestone, 2010; } \\
\text { Ho et al; Perkins, 2010; Fesharaki et al., } \\
\text { 2013: Fitzgerald, D.T., 2009; Sagnak, } 2010\end{array}$ & & & Contingent reward \\
\hline $\begin{array}{l}\text { Management } \\
\text { by exception }\end{array}$ & $\begin{array}{l}\text { Blankenship, 2010; Firestone, 2010; } \\
\text { Ho et al; Perkins, 2010; Fesharaki et al., } \\
\text { 2013: Fitzgerald, D.T., 2009; Sagnak, } 2010\end{array}$ & & & $\begin{array}{l}\text { Management } \\
\text { by exception }\end{array}$ \\
\hline
\end{tabular}

\section{Populasi dan Teknik Sampling}

Populasi penelitian adalah seluruh pegawai Badan Perencanaan Pembangunan Daerah Kota Bandung yang berjumlah 88 orang. Karena jumlah populasi relatif sedikit maka semua anggota populasi dijadikan sampel, sehingga penarikan sampel dalam penelitian ini menggunakan metode sensus. Teknik analisis data yang digunakan adalah analisis deskriptif dan kuantitatif dengan pendekatan SEM-PLS.

\section{HASIL}

Analisis model menggunakan program Smart PLS untuk mengetahui pengaruh dari variabel kepemimpinan transformasional dan kepemimpinan transaksional terhadap kinerja pegawai. Hasil analisis menunjukkan bahwa semua variabel laten memiliki korelasi yang lebih tinggi dengan konstruknya dibandingkan korelasinya dengan konstruk yang lain. Berdasarkan hasil uji validitas diskriminan, dari 24 item pertanyaan, terdapat 4 item yang dinyatakan tidak valid karena memiliki nilai AVE kurang dari 0.5 (lihat Tabel 2). Nilai composite reliability dan cronbachs alpha menunjukkan semua lebih besar dari 0.6 sehingga variabel dinyatakan reliabel (Hair et al., 2006).

Berdasarkan Tabel 3. dapat dilihat bahwa model sudah cukup baik menjelaskan pengaruh kepemimpinan transformasional dan transaksional pada kinerja pegawai. Model menunjukkan kinerja pegawai dipengaruhi oleh kepemimpinan sebesar 0.341 . Hal ini menunjukkan adanya faktor lain yang lebih menentukan kinerja pegawai daripada kepemimpinan. Secara parsial, semua hubungan dinyatakan signifikan karena memiliki nilai t-statistik lebih besar dari 1.96. Pengaruh kepemimpinan yang kecil pada kinerja pegawai dapat pula disebabkan oleh rentang kendali (span of control) yang terlalu lebar (Laschinger dan Wong, 2007). Jumlah bawahan yang terlalu banyak ditangani oleh seorang pimpinan akan menyebabkan lingkup dan intensitas keterlibatan pimpinan menjadi berkurang dalam pengambilan keputusan bawahan. Disamping itu, komunikasi menjadi kurang efektif dalam penyelesaian pekerjaan. Semua itu pada akhirnya menyebabkan efek positif dari kepemimpinan menjadi berkurang pada kepuasan kerja pegawai. 
Tabel 2. Koefisien Korelasi

\begin{tabular}{lrrr}
\hline & Kepemimpinan Transaksional & Kepemimpinan Transformasional & Kinerja Pegawai \\
\hline Kepemimpinan Transaksional & 1.000000 & 0.000000 & 0.000000 \\
Kepemimpinan Transformasional & 0.481046 & 1.000000 & 0.000000 \\
Kinerja Pegawai & 0.542306 & 0.451703 & 1.000000 \\
\hline
\end{tabular}

Tabel 3. Nilai Validitas dan Reliabilitas

\begin{tabular}{|c|c|c|c|c|}
\hline & AVE & Composite Reliability & R Square & Cronbachs Alpha \\
\hline Kepemimpinan Transaksional & 0.428367 & 0.814599 & & 0.743336 \\
\hline Kepemimpinan Transformasional & 0.375892 & 0.855927 & & 0.814065 \\
\hline Kinerja Pegawai & 0.469257 & 0.838169 & 0.341475 & 0.768101 \\
\hline
\end{tabular}

Tabel 4. Total Effects (Mean, STDEV, T-Values)

\begin{tabular}{lcccrr}
\hline & $\begin{array}{c}\text { Original } \\
\text { Sample (O) }\end{array}$ & $\begin{array}{c}\text { Sample Mean } \\
\text { (M) }\end{array}$ & $\begin{array}{c}\text { Standard Deviation } \\
\text { (STDEV) }\end{array}$ & $\begin{array}{c}\text { Standard } \\
\text { Error (STERR) }\end{array}$ & $\begin{array}{r}\text { T Statistics } \\
\text { (|O/STERR|) }\end{array}$ \\
\hline K. Transaksional $\rightarrow$ Kinerja Pegawai & 0.42287 & 0.42954 & 0.066621 & 0.066621 & 6.347406 \\
K. Transformasional $\rightarrow$ Kinerja Pegawai & 0.248282 & 0.263216 & 0.063243 & 0.063243 & 3.925854 \\
\hline
\end{tabular}

Untuk menguji bagaimana pengaruh kepemimpinan transformasional pada kinerja pegawai digunakan uji $\mathrm{t}$ dimana hasil menunjukkan nilai t-statistik lebih besar dari 1.96, yaitu 3.926. Dengan demikian kepemimpinan transformasional secara signifikan berpengaruh terhadap kinerja pegawai. Untuk mengetahui nilai kontribusi kepemimpinan pada kinerja dilakukan dengan menghitung nilai koefisien determinasi. Berdasarkan perhitungan, besarnya pengaruh kepemimpinan transformasional pada kinerja pegawai sebesar 0.112. Kontribusi kepemimpinan transformasional yang dijalankan pada Bappeda Kota Bandung dalam meningkatkan kinerja pegawai sebesar 11\%.

Pengujian bagaimana pengaruh kepemimpinan transaksional pada kinerja pegawai menunjukkan hasil signifikan karena menghasilkan nilai t-statistik sebesar 6.347. Berdasarkan perhitungan koefisien determinasi dapat diketahui besarnya kontribusi kepemimpian transaksional yang dijalankan di Bappeda Kota Bandung pada kinerja pegawai sebesar 0.229 .

\section{PEMBAHASAN}

Hasil penelitian ini menunjukkan bahwa untuk meningkatkan kinerja pegawai di Bappeda Kota Bandung, kepemimpinan transaksional lebih berperan daripada kepemimpinan transformasional. Hasil penelitian ini berbeda dengan kebanyakan hasil penelitian terdahulu yang menyatakan bahwa kepemimpinan transformasional lebih efektif dalam mendorong kinerja pegawai. Sebagai salah satu teori dari pendekatan contingency maka hal ini dapat dipahami karena pendekatan mana yang efektif tergantung pada situasi dan kondisi. Avolio et al. (1999) menjelaskan bahwa. kepemimpinan transformasional dengan sikap pemimpin yang menunjukkan karisma, inspirasional, perhatian secara individual, dan memotivasi pengembangan diri, tidak banyak berkontribusi dalam upaya meningkatkan kinerja pegawai. Timothy (2011) mengungkapkan bahwa dengan model kepemimpinan transformasional maka bawahan merasa percaya, merasa kagum, setia 
dan hormat terhadap pemimpin untuk lebih banyak memberikan dorongan. Pemimpin mendorong bawahan untuk lebih sadar akan kepentingan tugas dan membujuk untuk mendapatkan hasil yang lebih untuk kepentingan organisasi atau tim.

Kurang efektifnya penerapan kepemimpinan transformasional dalam mendorong kinerja mungkin disebabkan adanya ketidaksamaan antara sifat dan kepribadian pemimpin dengan lingkungan disekitarnya (Basham, 2010). Pendapat lain disampaikan oleh Rad dan Yarmohammadiyan (2006) yang mengatakan bahwa kepemimpinan yang cenderung partisipatif belum tentu efektif, harus memerhatikan budaya dan kedewasaan pegawai yang dihadapi oleh pemimpin. Mungkin saja pegawai bersedia untuk melakukan berbagai perubahan dan peningkatkan kinerja, namun bila pemimpin tidak didukung oleh lingkungan yang tepat, maka kepemimpinan transformasional tidak akan efektif. Birokrasi yang panjang dan tidak efisien, dukungan sarana dan prasarana yang tidak memadai, merupakan beberapa hal yang dapat menyebabkan kepemimpinan transformasional menjadi kurang memotivasi. Dalam hal ini kepemimpinan transaksional lebih besar kontribusinya dalam meningkatkan kinerja pegawai.

Kepemimpinan transaksional akan efektif bila organisasi memiliki standar, proses, dan prosedur untuk menjamin efisiensi, keadilan, dan kesetaraan dalam penerapan penghargaan dan imbalan (Basham, 2010). Kepemimpinan jenis ini dapat dijalankan bila pemimpin memiliki posisi yang kuat, dalam arti, pemimpin memiliki power yang besar untuk memengaruhi efektivitas standar, proses, dan prosedur pada organisasi. Kondisi tepat dijalankan di Bappeda Kota Bandung, sebagai sebuah instansi pada pemerintah Kota Bandung, maka Bappeda merupakan organisasi yang sudah memiliki aturan, standar proses dan prosedur yang baik. Pegawai akan termotivasi untuk mencapai kinerja yang tinggi bila pemimpin memiliki skill dalam menjalankan tugas dan fungsinya, memahami pekerjaan bawahan dan dapat memecahkan permasalahan teknis dengan baik.

Pradana (2013) dalam penelitiannya mengemukakan bahwa hubungan pemimpin transaksional dengan bawahan tercermin dari tiga hal yaitu: (a) pemimpin mengetahui apa yang diinginkan bawahan dan menjelaskan apa yang akan mereka dapatkan apabila kerjanya sesuai dengan harapan, (b) pemimpin menukar usaha-usaha yang dilakukan bawahan dengan imbalan, dan (c) pemimpin responsif terhadap kepentingan pribadi bawahan selama kepentingan tersebut sebanding dengan nilai pekerjaan yang telah dilakukan bawahan.

Bagi pegawai Bappeda Kota Bandung yang sebagian besar bertugas mendukung aktivitas perencanaan daerah, maka bila pemimpin terlihat ahli melalui kemampuannya untuk memberikan penjelasan tugas kepada bawahan, pemberian arahan pada bawahan, sehingga dalam memberikan pujian dan hukuman atas keberhasilan dan kegagalan pencapaian target, akan memotivasi dalam pencapaian kinerja.

\section{KESIMPULAN}

Hasil penelitian ini menunjukkan kepemimpinan transaksional lebih berperan dalam meningkatkan kinerja pegawai Bappeda Kota Bandung. Dalam hal ini pemimpin pada Bappeda Kota Bandung harus mensosialisasikan dengan baik seluruh aturan, standar proses dan prosedur serta semua ketetapan yang berlaku pada pegawai sehingga dapat menjalankan kepemimpinan transaksional dengan baik. Seorang pemimpin transaksional harus menunjukkan keahlian dalam bidang pekerjaannya dan menguasai permasalahan kinerja bawahan. Pemimpin menggunakan aturan dan standar sebagai alat yang mendukung timnya dalam mencapai tujuan. Oleh karena itu, sosialisasi dan penegakan aturan dan standar menjadi penting karena kemampuan pemimpin akan sangat membantu bawahan bila aturan dan standar ditegakkan.

\section{DAFTAR PUSTAKA}

Avolio, B., Bass, B., \& Jung, D. I. 1999. ReExamining The Components of Transformational and Transactional Leadership Using The Multifactor Leadership Questionnaire. Journal of Occupational and Organizational Psychology, 72: 441-462.

Basham, L. M. 2010. Presidents as Transformational or Transactional Leaders In Higher Education. Submitted To The Faculty Of The Graduate School Of Texas A\&M University-Commerce In Partial Fulfillment Of The Requirements For The Degree Of Doctor Of Education. 
Bass, B. M., B. J. Avolio, D. I. Jung \& Y. Berson 2003. Predicting Unit Performance by Assessing Transformational and Transactional Leadership. Journal of Applied Psychology, 88(2): 207-218.

Blankenship, S. L. 2010. The Consequences Of Transformational Leadership And/Or Transactional Leadership In Relationship To Job Satisfaction And Organizational Commitment For Active Duty Women Serving In The Air Force Medical Service. A Dissertation, School of Business and Entrepreneurship. Nova Southeastern University

Breaux, P. J. 2009. An Investigation of The Relationships Between Emergency Medical Technician's Ratings of Emergency Medical Service (Ems) Director's Transformational Leadership and Job Satisfaction in Rural Ems Environments. Dissertation Presented To The Faculty Of The Department Of Leadership Studies Our Lady Of The Lake University, San Antonio, Texas, March 11.

Chen, L. Y. 2004. Examining The Effect of Organization Culture and Leadership Behaviors on Organizational Commitment, Job Satisfaction and Job Performance At Small and Middle Sized Firms of Taiwan. Journal of American Academy of Business, 5(1/2): 432-438.

Fesharaki, M. G., Mohamadian, M., Aghamiri Z., Habib, M., Anvari, S., \& Marzabad E. A. 2013. Effect of Manager Leadership Behavior And Demographical Factors on Job Satisfaction in Military Healthcare Personnel. Iranian Journal Of Military Medicine, 15(1): 39- 44.

Firestone, Deborah T. 2010. A Study of Leadership Behaviors among Chairpersons in Allied Health Programs. Journal of Allied Health, 39(1).

Fitzgerald, D. T. 2009. Exploratory Study Of Leadership: Assessment Of Perceived Listening Skill And Leadership Style Of Nurse Leaders/ Managers. Submitted To Regent University School Of Global Leadership And Entrepreneurship, in Partial Fulfillment of The Requirements For The Degree of Doctor of Philosophy in Organizational Leadership.

Irawati, R. dan Liana, Y. 2013. Pengaruh Gaya Kepemimpinan Transformasional dan Kepuasan Kerja terhadap Kinerja Pegawai. Jurnal Ilmiah ESI, 7(3).
Hancock, C. S. 2008. The Effects of Leadership in Veterinary Hospitals on Employee Satisfaction And Culture. A Dissertation Presented In Partial Fulfillment of The Requirements For The Degree Doctor of Business Administration School of Advanced Studies, University of Phoenix.

Ho, J. S. Y., Fie, D. Y. G., Ching, \& Ooi, K. B. 2009. Relationship Between The Full-Range Leadership And Insurance Salesperson's Job Satisfaction. International Journal of Business And Management Science, 2(1): 43-60.

Kim, H. 2009. Transformational And Transactional Leadership of Athletic Directors And Their Impact on Organizational Outcomes Perceived By Head Coaches At NCAA Division II Intercollegiate Institutions. Dissertation Presented in Partial Fulfillment of The Requirements For The Degree Doctor of Philosophy, The Ohio State University. Locander, W. B., Hamilton, F., Ladik, D. \& Stuart, J. 2002. Developing a Leadership-Rich Culture: The Missing Link to Creating a Market-Focused Organization. Journal of Market-Focused Management, 5: 149-163.

Mangkunegara, A. A. P. 2009. Evaluasi Kinerja Sumber Daya Manusia. Bandung: Refika Aditama.

Maulizar, Musnadi, S, dan Yunus, M. 2012. Pengaruh Kepemimpinan Transaksional dan Transformasional terhadap Kinerja Pegawai Bank Syariah Mandiri Cabang Banda. Jurnal Ilmu Manajemen, Pascasarjana Universitas Syiah Kuala.

Muhardi dan Siregar, M. R. 2013. Pengaruh Kepemimpinan Transformasional dan Transaksional Terhadap Kinerja Pegawai Badan Investasi dan Promosi Aceh. Jurnal Ekonomi Manajemen dan Bisnis, 1(1): 99-117.

Perkins, L. D. 2010. Nurse Managers Transform Nursing: A Study Of Leadership Behaviors And The Relationship To Leadership Training And Employee Satisfaction. A Dissertation Presented In Partial Fulfillment Of The Requirements For The Degree Doctor Of Philosophy, Capella University.

Pradana, M. A. 2013. Pengaruh Gaya Kepemimpinan Transformasional dan Transaksional Terhadap kinerja Pegawai PT Mustika Bahana Jaya Lumajang. Jurnal Ilmu Manajemen, 4(2). 
Rad, A. M. M. dan Yarmohammadian, M. H. 2006. A Study Of Relationshop Between Manager's Leadership Style And Employees Job Satisfaction. Leadership In Health Service, 19(2): XI-XXVIII.

Raja, M. P. N., Deshmukh, S. G., dan Wadhwa, S. 2007. Quality Award Dimensions: A Strategic Instrument For Measuring Health Service Quality. International Journal Of Health Care Quality Assurance, 20(5): 363-378.

Robbins, S. P. 2008. Perilaku Organisasi. Edisi Bahasa Indonesia, Alih Bahasa, Benyamin Molan (Edisi Ke-10). Jakarta: Indeks.
Sağnak, M. 2010. The Relationship Between Transformational School Leadership And Ethical Climate. Kuram Ve Uygulamada Eğitim Bilimleri / Educational Sciences: Theory \& Practice, 10(2): 1135-1152.

Sedarmayanti. 2007. Manajemen Sumber Daya Manusia: Reformasi Birokrasi dan Manajemen Pegawai Negeri Sipil. Bandung: Refika Aditama. Timothy C. O. et al. 2011. Effect of Leadership Style on Organizational Performance. Australian Journal of Business and Management Research, 1(7): 100-111. 